\title{
Perceptions of dental therapy students regarding the teaching and training with dental amalgam, in a dental school in KwaZulu-Natal, South Africa
}

SADJ June 2021, Vol. 76 No. 5 p258 - p269

S Bissoon ${ }^{1}$, R Moodley ${ }^{2}$

\section{INTRODUCTION}

Dental amalgam has been used as a restorative material in dentistry for the past 150 years. This material has been used to restore posterior teeth throughout the world and is also used in South Africa.

Dental amalgam has been the material of choice for patients presenting with large tooth decay areas, including the loss of cuspal areas. ${ }^{1}$ The reason for this is that dental amalgam was always considered strong and durable. Compared to alternate dental materials, this material could also withstand the significant forces associated with chewing and biting. ${ }^{2}$ Dental amalgam is also considered more cost-effective than alternate dental materials such as conventional glass ionomers, resin-modified glass ionomers, resin composite and ceramic restorations, making it more feasible and material of choice in lower economic countries, including South Africa. ${ }^{3}$

Due to the increased awareness of mercury toxicity, there has been an introduction of alternate dental materials such as glass ionomers, resin ionomers, and resin composites. ${ }^{2}$ Resin composites have been available for the past 40 years. ${ }^{3}$ During this time, numerous developments have been made to improve the material's strength and aesthetics. Resin composites are now the material of choice due to their high aesthetic value. Resin composites also require minimal tooth preparation, resulting in the conservation of a healthy tooth structure. ${ }^{3}$

\section{Author affiliations:}

1. Sharmila Bissoon: B. Oral Health; B. Dental Therapy; PG Dip Public Health, Master's student, Discipline of Dentistry, University of KwaZulu-Natal.

2. Rajeshree Moodley: PhD, Lecturer, Discipline of Dentistry, University of KwaZulu-Natal. ORCID Number: 0000-0003-2703-9370

Corresponding author: Rajeshree Moodley

University of KwaZulu-Natal.

Email: moodleyra@ukzn.ac.za

Author contributions:

1. Sharmila Bissoon: Study design, data collection, data analysis, and drafting the manuscript, read and approved the final manuscript - $50 \%$

2. Rajeshree Moodley: Supervision of the entire work, study design, and manuscript review, read and approved the final manuscript $-50 \%$
They are generally micro-mechanically bonded to the tooth, which results in the tooth's overall strength. The newer composite materials are also more durable and, therefore, comparable to amalgam restorations in terms of strength. However, documented studies by Fernandes, Vally and Sykes (2015) and Hurst (2014) reveal that a composite restoration's survival rate is lower than an amalgam restoration in the long-term evaluation. ${ }^{4,5}$ This is due to polymerisation shrinkage, which occurs during the setting reaction, resulting in microleakage underneath the restoration.

Another disadvantage of a composite restoration is the difficulty in achieving tight contact between teeth due to poor matrix band application. This results in secondary caries, which in turn requires the replacement of the restoration. ${ }^{6}$ There are now advances in matrix systems and composite materials and the improved skills and expertise of the practitioner. We can now look at replacement rather than repair. ${ }^{7}$

The earlier composite material, the micro fills, lacked condensable properties and strength and were not used in load-bearing areas such as posterior teeth. Now bulkfill composite material has been introduced. ${ }^{8}$

The Minamata Convention was an international conference that was held in October 2013 in Kumonata, Japan, which included delegates from 140 countries, including South Africa. ${ }^{9}$ This treaty was introduced to protect human and environmental health from the emissions and release of mercury and mercury compounds.

The Minamata Convention also called for a phase-down approach to dental amalgam through greater emphasis on prevention, research into new dental materials, and best management practice regarding amalgam disposal. ${ }^{10}$ In November 2019, the parties considered a proposal to phase out dental amalgam by 2024, except in cases where no alternative is available. ${ }^{11}$

This study was conducted at the dental faculty of the University of KwaZulu-Natal, South Africa, to gain insights from the students regarding their perceptions about dental amalgam training. 
The School of Dentistry is located within the Faculty of Health Sciences. The programmes offered include the Degree in Dental Therapy and in Oral Health. Teaching in the basic and social sciences and the preclinical components occur at the Westville campus. All clinical teaching occurs at the Oral and Dental Training Centre, in Sydenham, KwaZulu-Natal. ${ }^{12}$

The scope of practice of dental therapists in South Africa is considered more extensive than in most other countries. ${ }^{13}$ They can treat adults and children and do not require any supervision from dentists or dental therapists once they have completed their mandatory service. ${ }^{13}$

\section{METHODOLOGY}

This was a descriptive cross-sectional case study conducted between February and June 2020 to determine undergraduate dental students' knowledge and attitudes towards the use of dental amalgam in the current dental training curriculum.

A combination of quantitative and qualitative data was obtained to ensure that the data's strengths and limitations were balanced. This helped to ensure greater understanding by integrating both types of data. ${ }^{14}$

The study site was the University of KwaZulu-Natal, a university with five campuses in KwaZulu-Natal in South Africa. UKZN is one of two universities in the South that offers the Bachelor of Dental Therapy degree.

All participants in this study included dental therapy students $(n=109)$ because the university, at this stage, was not enrolling oral hygiene students. The response rate was nearly $70 \%$. The second- $(n=50)$ and third-year $(n=59)$ students participated in the study. Students in the first year of study were excluded because they had no experience in restorative dentistry. Students in the second year of study are introduced to dental materials in the lectures and have preclinical laboratory training on the phantom head and observe the third-year students in the clinic while working on patients. The third-year students are involved in clinical training at the Oral and Dental Hospital, where they perform restorative procedures.

Data captured from the questionnaire were entered into Microsoft Excel and analysed using Statistical Package for the Social Science (SPSS), version 26. Descriptive and inferential statistics were calculated, including the percentage and $95 \%$ confidence interval positive response to questions. A Chi-square test was used to test the associations between variables. All the tests are two-tailed, and the criterion for statistical significance was set at $5 \%$ level. ${ }^{15}$

\section{Data collection}

The research instrument included a self-administered questionnaire comprising both open-ended and closed-ended questions. Open-ended questions were used to allow the participants to express themselves to answer based on their complete knowledge, feeling and understanding of the topic. An example was, "Do you feel that the univer- sity prepared you adequately to place restorations, provide a reason". The open-ended questions analysis from the students' responses contributed to the study's qualitative method.

The questionnaire included 20 items designed to assess students' knowledge and perceptions regarding the use of dental amalgam, both in the preclinical laboratory and the dental clinic. The first part of the questionnaire consisted of sociodemographic data, such as age, sex, year of study, knowledge of dental amalgam, and understanding of the relationship between what is taught and what is practised.

The second part of the questionnaire included variables, such as exposure to various dental materials, the first dental material introduced to the phantom head, clinical training time for dental amalgam, clinical training time for resin composite, and the material used more often on outreach programmes. The questionnaire also included questions on the choice of dental material used in the clinic, the clinical supervisor's influence on the type of material used, and the type of cavity design preparations.

The questionnaire also included questions regarding knowledge of the Minamata Convention and the phase-down of dental amalgam. The third part of the questionnaire focused on the knowledge regarding trends in other countries regarding the use of dental amalgam and whether composite should completely replace amalgam in dental training. Scientific validity is applicable in quantitative research andis concerned with how an assessment tool measures what it is intended to measure. ${ }^{16}$ This questionnaire was designed to allow the researcher to achieve the intended aims and objectives for this study.

Reliability in quantitative study design can reproduce the same results if a particular instrument is used at different times and by different researchers. ${ }^{16}$ Reliability was maintained by double-checking the data during data entry and was verified by the research supervisor.

\section{Ethical approval}

The study was granted ethical clearance by the Humanities and Social Sciences Research Ethics Committee at the University of KwaZulu-Natal (ref. no. HSSREC/00 000622/2019). Gatekeeper permission was also granted from the registrar at UKZN. Written informed consent was obtained from all participants. Students were made aware that the study was voluntary and that participants were free to withdraw from the study at any stage without any negative consequences.

The questionnaire was administered in the English language after confirming that all the participants were comfortable with the language. All other ethical issues, such as confidentiality and anonymity, were maintained. Data were analysed using SPSS version 26.0 (IBM Corp., USA). The responses to the open-ended questions were grouped, and emergent themes were examined and compared for possible associations. Inferential techniques included Pearson's $\chi 2$ test to assess a possible relationship between the independent variables (age, sex, and year of study) and the dependent variables (first material used 
in the preclinical dental laboratory, and use of dental material in outreach programmes). A $p<0.05$ level was established as being significant.

The participants were given codes to identify them when the responses to the open-ended questions were pre sented: Second-year students were numbered from P1 $-\mathrm{P} 41$, and the third-year students were numbered from Pi- Pxxxiv.

\section{RESULTS}

One hundred and nine questionnaires were distributed among the second- and third-year dental therapy students. Seventy-five questionnaires were returned, yielding a $70,75 \%$ response rate. The response rate was in proportion to the population total, i.e., 34 students in the third year of study and 41 students in the second year of study. In the second year, the gender distribution of students comprised an almost equal distribution of females $51,22 \%(n=21)$ to males $48,78 \%(n=20)$.

The third-year students were mostly female $85,3 \%$ ( $n=$ 29) with $14,7 \%(n=5)$ males. The data collected was presented separately for the second- and third-year students, as the second-year students were involved in preclinical training in a skills laboratory and assisted and observed the third-year students in the clinic. The thirdyear students had performed restorations on patients.

The separation of the results helped prevent the data from being skewed and to prevent bias. However, both the second- and third-year students were given lectures and tutorials on dental amalgam as well as other dental materials.

\section{Knowledge regarding dental amalgam training}

\section{Second-year students}

The results of the data gained from the questionnaires revealed that $100 \%(n=41)$ of second-year students indicated that the first material introduced in the preclinical laboratory was resin composite. Approximately eighty-five percent $(n=35)$ of the students had also indicated that more than $50 \%$ of their preclinical time was spent on teaching and training in resin composite and other dental materials. $60,5 \%$ ( $n=25)$ of students indicated that they did not have adequate training in the various types of cavity design preparations. 36,6\% $(n=16)$ indicated that they had sufficient exposure to the various types of material in the dental clinic. 55\% $(n=23)$ second-year students indicated that they felt that the university prepared them adequately to place restorations.

\section{Third-year results}

The third-year students' findings indicated that $85,3 \%$ $(n=29)$ were female, and $14,7 \%(n=5)$ were male. Approximately seventy-five percent $(n=25)$ agreed that the university prepared them adequately to place restorations, $17,65 \%(n=6)$ were unsure (neutral), and $8,8 \%$ $(n=3)$ disagreed that the university had prepared them sufficiently to place restorations. Students also had vary- ing responses with regards to them having adequate exposure to the various types of dental materials available in the clinic: $50,1 \%(n=17)$ agreed, 38,2\% $(n=13)$ were unsure (neutral), and $11,7 \%(n=4)$ disagreed.

\section{Preparedness of students}

Students' preparedness was an indication of whether students felt that they were sufficiently prepared to per form cavity preps for amalgam and composite restorations and if they felt that they had enough exposure to the different types of material required for restorative dentistry.

\section{Second-year students}

The qualitative data analysis indicated some of the reasons students felt that they did not have adequate exposure to the various types of cavity preparations $60,5 \%$ $(n=25)$.

One of the reasons stated for this was firstly a large number of registered students. The following statements supported this:

P2: "Due to the large number of students in this degree, we do not get much time to practice."

P3: "There were many students, and due to that, it was hard to be taught properly."

P4: "Due to large class sessions, everyone does not get adequate exposure to perform restorations."

P17: "not enough practice"

P38: "We had a short time to learn everything about restorations."

Some of the responses from participants who felt that the university prepared them sufficiently to place restorations are as follows:

P5: "There was plenty of restorative pracs in the lab." P23: "We are taught things that we are supposed to know, no time wasted on things we don't need to know."

P16: "Because they gave us important information for restoration placement."

P27: "very well trained lecturers."

\section{Third-year students}

The following quotes justify some of the reasons given by the students who agreed that the university prepared them sufficiently to place restorations:

Pv: "I know the different materials and how to manipulate them for different situations and restoring and constructing is my favourite compared to extractions."

Pvi: "Learnt all about recent materials, cavity design and minimal intervention dentistry."

Pviii: "The clinical practical were so useful."

Pxxiv: "Subject was well done in which we manage to know the advantage and disadvantage, the indications and contra indication and the chemistry of the dental, materials." 
Pxvii: "The lectures and notes that were given were detailed and I found it very useful. It gives explanations and reasons why you need to prepare your cavity in such a way, and also we learnt about the properties of materials and how to manipulate these."

Pxii: "Adequate information were given about restorative materials and which one is more effective. My knowledge has increased about their properties and it's use."

Approximately $11.2 \%(n=4)$ of students did not agree that the university prepared them sufficiently to place restorations. Some of the responses stated by the participants were as follows:

$\mathrm{Pi}$ : "Students are not adequately prepared as demonstrations were done only once in groups of 20 students, as well as inadequate exposure to patients due to lack of equipment and a large number of students."

Pii: "We had learnt the basics that would enable us to place restorations, but this could have been improved by increased exposure to various materials and techniques."

Piii: "There was not enough clinical exposure throughout the year."

Piv: "Hardly got to do amalgam restorations and as a result, feel that I lack the skill to do an amalgam as more time went spent doing and getting used to composite materials."

Students were satisfied with the lectures and tutorials. However, due to the limited time and large class numbers, $11.2 \%(n=4)$ felt that they did not have enough practical training in placing the various types of dental materials.

\section{The practice of students using dental amalgam}

\section{Second-year students}

The findings indicate that $100 \%(n=41)$ of students indicated that composite resin was the first dental material introduced to them in the preclinical laboratory. This was also the material that their respective supervisors encouraged them to use.

The reason for this, as stated by the participants, was because composite material was:

P2: "safer than amalgam".

P39: "you need one session to finish".

P38: "better aesthetics and minimal cavity prep".

P33: "for aesthetics and easier to use".

P14: "they say that it is easier to use".

Hundred percent of second-year students indicated that composite resin was the material that they used more often in the preclinical laboratory for all one, two, and three surface restorations. The reasons given for their choice of material, for the majority of students $(29 \%, n=$ 12) was the ease of use (manipulation of the material), $24.3 \%(n=10)$ indicated aesthetics as a contributing factor, $22 \%(n=9)$ felt that safety of material was their reason of choice, and $12.3 \%(n=5)$ indicated that cost and patient preference, $12.3 \%(n=5)$, was a factor. The data also showed that $73.2 \%$ ( $n=30$ ) of students used composite resin for complex restorations (4 surface and more).

The reason for their choice was given as: P38: "composite has better aesthetics and is not sensitive to temperature."; P39: "composite has better aesthetic and less mercury toxicity"; P16: "easy manipulation"; and the fact that P6: "composite was the only material that we have been exposed to thus far".

Almost twenty-seven percent $(n=11)$ of students agreed that they would use dental amalgam for complex restorations. The following quotes justified this: P2: "amalgam is stronger and more load-bearing compared to composite"; P11: "provides more physical strength and compressibility"; P19: "amalgam is more strong and has higher compressive strength"; P17: "a lot more strength, less prone to breakage".

\section{Third-year students}

Sixty percent $(n=20)$ of students indicated that less than $50 \%$ preclinical training was done on dental amalgam. Eighty-three percent $(n=28)$ of students indicated that more than $50 \%$ of phantom head training in the dental laboratory was practised on other dental materials, such as resin composite. Nearly ninety-two percent $(n=31)$ indicated that they used resin composite material more often in the dental clinic.

Eighty percent $(n=27)$ of students indicated that they inform patients regarding the type of material used. The predominant reason for their choice of dental material (composite) was, firstly aesthetics $35 \%(n=12)$, secondly, patient preference $(23,5 \%, n=8)$, thirdly, safety $(20,5 \%$, $n=7)$, fourthly, ease of use (manipulation) $(15 \%, n=5)$, and lastly, cost $(6 \%, n=2)$ which was the least contributing factor.

Nearly $88 \%(n=30)$ of students indicated that their dental supervisors encouraged them to use resin composite more often in the clinic. The reason for this was "better aesthetic", "phasing down of amalgam", and "minimal loss of tooth structure". It was indicated that supervisors encouraged the use of resin composite. The reasons for this was Pii: "supervisors want to improve our composite restorative technique as they recognise that composite is the most widely used material in private practice, which is where the majority of students will end up working".

Approximately forty-four percent of students $(n=15)$ of students use composite material more often on dental outreach programmes, $12,5 \%(n=4)$ use glass ionomer, and $15,6 \%(n=5)$ use dental amalgam. Almost ninety-two percent of participants $(n=31)$ have indicated that they have seen resin composite being used more often in private practice. $100 \%(n=34)$ of third-year students indicated that they use resin composite more often for one, two, and three surface restorations. $35,3 \%(n=12)$ of students use dental amalgam more often for complex restorations (4 surfaces and more).

In the third year, students use both types of material, i.e., amalgam and composite, in their clinical training. The students were asked which material they used more often 
for class 1, class 2, and complex restorations. Figure 1, below, indicates their choice of material.

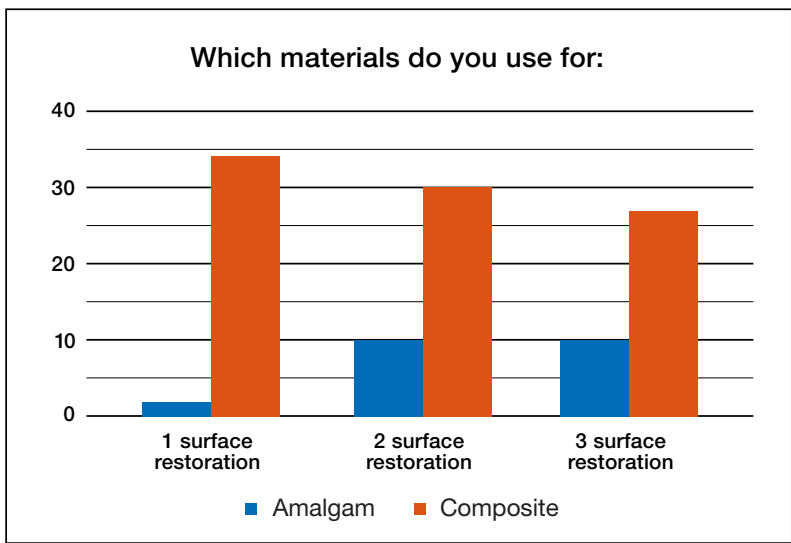

Figure 1. The material used by third-year students for 1, 2, 3 surface restorations

The qualitative data gained in support of dental amalgam being used for complex restorations are as follows:

Some of the reasons given by about thirty-five percent $(n=12)$ of third-year students for using dental amalgam in complex restorations are as follows:

Pviii: "it is stronger and last longer, have good compressive strength, most complex cavities are in posterior teeth, so there is not much need for aesthetics."

Pvi: "More adept with using amalgam, also if in a high load-bearing area, amalgam is more durable."

Pvii: "Amalgam may be considered for more complex restorations as strength is of main importance and amalgam has more to offer when it comes to strength and durability than composite."

Pxvi: "if posterior teeth can withstand occlusal forces."

Pxix: "it is more durable and more easily packable."

Approximately sixty-five percent of the third year $(n=22)$ students indicated that they use composite resin for more complex restorations, and the reasons given to justify this choice are as follows:

Pxv: "Composite is bonded, which makes it reliable and more conservative, also for aesthetics."

Pxxxii: "I love composite and trust it for improved aesthetics, easy to handle and polish-ability plus no health hazards as compared to amalgam."

Pii: "Composite bonds to tooth structure thereby strengthening the tooth as opposed to amalgam which looks un-aesthetic in a large cavity prep."

Pxvii: "it involves minimal invasive intervention, less removal of tissues, and the ability of the material to bond to tooth surfaces."

Pxxxv: "to enhance retention, preserve tooth structure."

\section{Choice of dental material}

The second- and third-year students were asked what their main reason was for choosing dental material when restoring a tooth was. The main reasons that emerged were aesthetics, cost of material, ease of use, material safety, and ease of manipulation.

The responses were presented on a graph so that a comparison can be seen between the second- and third-year students.

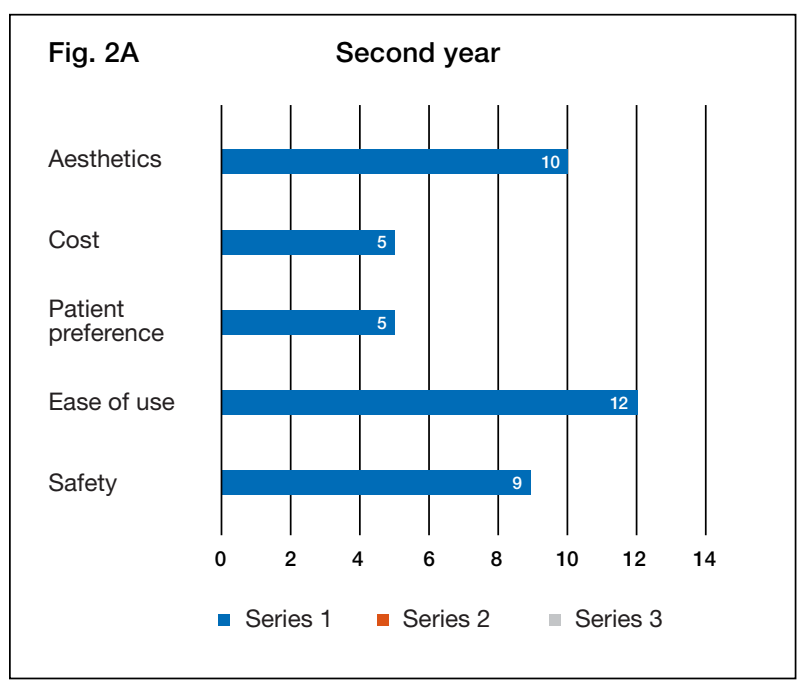

Fig. 2B Third year

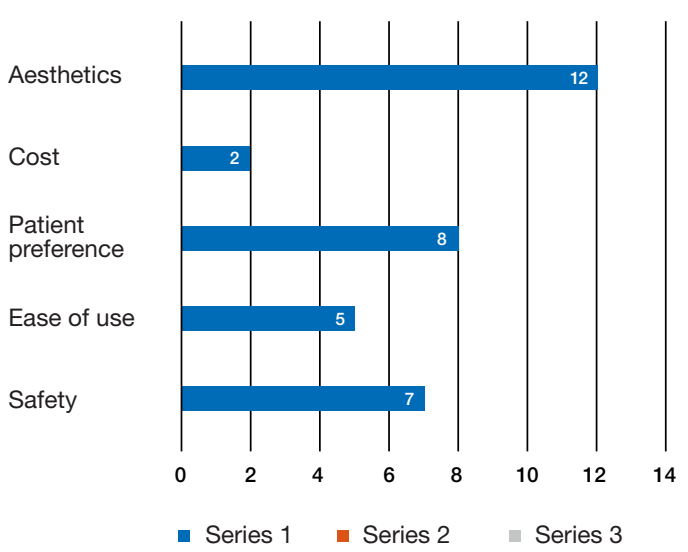

Figure 2. A comparison between the second-year preclinical student and the third-year clinical students regarding their choice of material.

The above figures (2A and $2 \mathrm{~B}$ ) illustrate why students consider their choice of restorative material.

Ease of use (manipulation) of the dental material was the main contributing factor for the choice of material for second years $(30 \%, n=12)$, while aesthetics was the main reason for the choice of material for the third year $(35,29 \%, n=12)$.

\section{Minamata convention and amalgam usage internationally}

The majority of second-year students indicated that they have not heard of the Minamata Convention and 82,1\% $(n=34)$ of the students stated that they were not aware 
of the phase-down of dental amalgam. Almost eighty percent $(n=27)$ of third-year students have heard of the Minamata Convention, and $73,5 \%(n=25)$ of students are aware of the phase-down of dental amalgam.

5.1. Students were asked a question as to why amalgam is banned in some countries. There was a $91 \%$ response to this question.

The main reason that emerged from both the secondand third-year participants was the mercury content in amalgam.

The participants answered as follows:

\section{Second-year students}

P9: "because of mercury exposure."

P13: "because of mercury release and is not aesthetically pleasing."

P27: "people are concerned about the mercury issue."

P14: "due to the controversy about mercury toxicity."

\section{Third-year students}

Pvii: "Because certain countries are strict against the dangers of mercury toxicity. I even had a patient whose old amalgam had come off, and she didn't want us to put another amalgam restoration as she had read on the internet that it is dangerous to your mental health, so a lot of people do not fully trust the use of it and would rather just not use it."

Pii: "there is a risk mercury toxicity as well as a harmful impact on the environment if not disposed of correctly."

Pvi: "the mercury scare on all forms of media, studies showing mercury unsafe."

Pxx: "too many lobbyists for tooth-coloured material and business-minded."

Pxv: "it doesn't meet aesthetic requirements and minimal inversion (invasion technique)."

5.2. Students were questioned as to why dental amalgam is still used in some countries such as South Africa and America. There was a $97 \%(n=33)$ response to this question. The predominant factor that emerged was the cost of the material, and is validated by the following quotes:

\section{Second-year students}

- P1: “... it's cheaper..."

- P2: "cost-effective, cheaper than other dental restorative materials."

- P3: "cost less and is durable."

- P4: "cheaper for the patient, and for the ease to handle."

\section{Third-year students}

Pxiv: "because of its strength and longevity, also cheaper than composite."

Pxxvii: "it is because of cost. People can afford to pay."
Pxii: "it is the strongest material, easy to use and cheaper than composites."

Pvi: "other studies showing high performance and durability of amalgam. Relative ease of use (not technique sensitive) and relatively lower cost."

Pvii: "I think because they haven't had many cases of people refusing amalgam, the people aren't aware of mercury toxicity as other people in other countries."

6. The participants were asked whether they felt that resin composite should completely replace dental amalgam in dental training.

Approximately seventy-three percent $(n=30)$ of second-year students indicated that composite should replace amalgam in dental training, while $26,8 \%(n=11)$ of students indicated that amalgam should not be replaced in dental training. Some of the reasons that emerged from the participants who agreed that dental amalgam should be replaced by resin composite are as follows:

\subsection{Aesthetics and bonding to the tooth structure}

Aesthetics is a significant factor in students' choice of material, as patients are becoming more aesthetically aware and demanding aesthetically pleasing material not just for anterior teeth but also for posterior teeth.

Students are also highly aware of conserving tooth structure, therefore preparing cavities with minimal loss of healthy tooth structure. The students have justified their reasons with the following responses:

\section{Second-year students}

Approximately twenty-four percent of second-year students considered aesthetics as a contributing factor in their choice of material. The following quotes support this:

P2: "it is easier to handle and more aesthetically pleasing." P3: "... aesthetically, it is better..."

P37: "it is safe, tooth coloured, easier to use, patients pre fer it."

P35: "Resin composite has good aesthetics, conservative...much safer than amalgam."

Second-year students stated that bonding to the tooth structure and minimal cavity preparation was another reason they agreed that composite should replace amalgam in dental training. The following quotes confirm this:

P35: "Resin composite has good aesthetics, conservative... much safer than amalgam."

P11: "Easier to use...smaller cavity design."

P22: "Resin composite is safer and better bonding to the tooth."

P39: "resin composite is easy to use, less toxic...requires less sized cavity prep."

\section{Third-year students}

Students were asked if they felt that resin composite could completely replace amalgam in dental training. 
Approximately $41 \%$ were unsure (neutral), 35\% agreed that amalgam should be replaced, and $20,6 \%$ disagreed that dental amalgam should be entirely replaced by composite. The participants presented the following responses, as to the influence that aesthetics and bonding to tooth structure have on their reason for dental amalgam being replaced:

Piii: "because composite uses minimal invasive technique, therefore saves more tooth structure than amalgam."

Pxxiii: "because of aesthetics, amalgam don't have the same colour as teeth."

Pxiv: "amalgam is still the strongest material being used today, but composite has a few advantages... like being aesthetic and easy to manipulate."

Pvii: "Even in private practice, we see that amalgam use is fading away...the point is that patients do not want it due to aesthetics."

Pxxxii: "Composite have no health hazards, it improves aesthetics, plus it is easy to handle."

\subsection{Mercury toxicity}

Students were asked their reasons for responding that amalgam should be replaced by dental composite. A major contributing factor that had emerged was the toxicity of dental amalgam due to the mercury content. The second-year students justified this response with the following quotes:

P41: "amalgam may be toxic to the oral cavity because of its content of mercury."

P36: "because amalgam results in galvanism... not safe."

P42: "because of the environmental dangers as it contains mercury."

The third-year students responded with the following quotes:

Pii: "There is a risk of mercury toxicity as well as a harmful impact on the environment if not disposed of correctly."

Pxii: "Because of mercury release, and it is not aesthetically appealing."

Pxi: "Because of the environmental dangers, as it contains mercury."

\section{Compressive strength of amalgam}

Participants were asked to explain why they felt that dental amalgam should not be replaced by composite. The compressive strength of amalgam emerged as the main contributing factor.

\section{Second-year students}

Approximately twenty-seven percent of second-year students felt that dental amalgam should not be replaced by resin composite in dental training. The strength of amalgam was the major contributing factor:

P33: "it is strong."

P23: "composite is not as strong."

P18: "amalgam is the strongest."

P17: "amalgam will remain the material of choice for generations to come."

\section{Third-year students}

Approximately twenty-one percent of third-year students felt that amalgam should not be replaced with a dental composite. The main reason that emerged from the qualitative data was due to the compressive strength of amalgam. Some of the responses are as follows:

Piv: "In some extensive preps, composite cannot replace amalgam as a higher strength would be needed."

Pxiii: "Composite can never replace amalgam... Composite can easily fail in cavities in which amalgam will last for years. So I cannot say amalgam should be replaced by composite in training. My opinion on amalgam is: Phase it down? Yes. Replace it? No."

Pxxv: "We still need amalgams in complex posterior preparations."

Pxx: "Amalgam will remain the material of choice for many generations to come"

Px: "Still strongest material. Placed properly should not pose a problem. Students should be taught how to handle amalgam responsibly. Both restoration material has its strong and weak points. In cases where composite cannot be placed amalgam can be used."

Pii: "I think that composites should be used as a first choice but should not replace amalgam altogether. Amalgam can be used in instances of composite failure and where economics and moisture control is an issue."

\section{DISCUSSION}

In this study, there were more female than male participants. This is in line with a South African study investigating the dental therapy cohorts at a South African university. The study found a progressive rise in the proportion of female student enrolments during the decade between 2004 and 2014 (51.5\% in the first year, 55.6\% in the second year, and $60.9 \%$ in the third year of study, respectively). ${ }^{17}$

The teaching of posterior composites is well established in dental training in the UK, Ireland, United States, Canada, Japan, Spain, Brazil, and Iran. ${ }^{18}$ Students in the UK and Ireland gain more experience in posterior composite placement than dental amalgam. ${ }^{18}$ This change in the teaching trend is due to the shift towards minimally invasive dentistry. ${ }^{18}$

The minimal intervention approach focuses more on the prevention and detection of dental caries at its earliest. If restoration is required, a minimally invasive technique is 
used that conserves as much tooth structure as possible. The minimally invasive technique uses adhesive materials such as glass ionomer cements and resin composites. The micro-mechanical bonding that bonds the restoration to the tooth structure allows for minimal removal of healthy tooth structure, negating the conventional GV Black cavity design.

The new techniques for minimal cavity design include sonic techniques, air abrasion and bioactive glasses, chemomechanical treatment and the atraumatic restoration technique. ${ }^{19}$ In our study, it was found that more time was spent on composite in both preclinical and clinical training.

Pre-clinical skills experience in the restoration of posterior teeth is now on composite material, rather than amalgam, for most students. ${ }^{18}$ Therefore, it is anticipated that the future generation of dentists and dental therapists joining the dental professional workforce will be more skilled in the placement of composite restorations than amalgam. Therefore, this generation will be more conservative in their approach to cavity design. GV Black's old approach, "extension for prevention", has been transformed into a more preventively orientated, patient-centred approach. In most UK dental schools, amalgam placement is no longer taught on child patients. ${ }^{20}$

According to a previous American Dental Association survey, posterior composite resin restorations now outnumber amalgam restorations in the United States. ${ }^{21}$ A study conducted in Ibadan, Nigeria, found that amalgam, as a choice of restoration material, was gradually being replaced by composite. ${ }^{22}$ Our survey also recorded a reduction in amalgam usage by both students and clinical supervisors.

In South Africa, it was stated that developing countries would face a challenge to phase-down amalgam due to the lack of comparable alternative restorative materials. This was due to the high cost and technique sensitivity of the restoration, which increases dental care costs. ${ }^{23}$ However, due to the UN treaty from the Minamata convention, a phase-down of dental amalgam is necessary to reduce mercury exposure. It was recommended that

\begin{tabular}{|c|c|c|c|c|c|}
\hline \multirow{3}{*}{ Variables } & \multicolumn{4}{|c|}{$\begin{array}{l}\text { Do you feel that resin composite should replace } \\
\text { amalgam in dental training? }\end{array}$} & \multirow{3}{*}{$\begin{array}{l}\text { Fisher } \\
\text { Exact } \\
\text { P-value }\end{array}$} \\
\hline & \multicolumn{2}{|c|}{ Yes } & \multicolumn{2}{|c|}{ No } & \\
\hline & $\mathbf{N}$ & $\%$ & $\mathbf{N}$ & $\%$ & \\
\hline \multicolumn{6}{|l|}{ Gender } \\
\hline Male & 14 & $70.0 \%$ & 6 & $30.0 \%$ & \multirow{2}{*}{0.655} \\
\hline Female & 16 & $76.2 \%$ & 5 & $23.8 \%$ & \\
\hline \multicolumn{6}{|c|}{$\begin{array}{l}\text { Do you think that you had adequate exposure to the various } \\
\text { types of restorative materials, used in the clinic? }\end{array}$} \\
\hline Yes & 10 & $66.7 \%$ & 5 & $33.3 \%$ & \multirow{2}{*}{0.475} \\
\hline No & 20 & $76.9 \%$ & 6 & $23.1 \%$ & \\
\hline \multicolumn{6}{|c|}{$\begin{array}{l}\text { Do you think that you had adequate training in the various } \\
\text { types of cavity design preparations? }\end{array}$} \\
\hline Yes & 12 & $80.0 \%$ & 3 & $20.0 \%$ & \multirow{2}{*}{0.475} \\
\hline No & 16 & $69.6 \%$ & 7 & $30.4 \%$ & \\
\hline \multicolumn{6}{|c|}{$\begin{array}{l}\text { What was the first dental material that you were introduced to } \\
\text { in the dental clinic? }\end{array}$} \\
\hline Composite & 29 & $72.5 \%$ & 11 & $27.5 \%$ & - \\
\hline \multicolumn{6}{|c|}{$\begin{array}{l}\text { How much of clinical training time was spent on the teaching } \\
\text { and training of amalgam? }\end{array}$} \\
\hline$<50 \%$ & 25 & $71.4 \%$ & 10 & $28.6 \%$ & \multirow{2}{*}{0.543} \\
\hline$>50 \%$ & 5 & $83.3 \%$ & 1 & $16.7 \%$ & \\
\hline \multicolumn{6}{|c|}{ How much of clinical training time was spent on alternate dental materials? } \\
\hline$<50 \%$ & 9 & $75.0 \%$ & 3 & $25.0 \%$ & \multirow{2}{*}{0.817} \\
\hline$>50 \%$ & 20 & $71.4 \%$ & 8 & $28.6 \%$ & \\
\hline \multicolumn{6}{|l|}{ One surface restoration use } \\
\hline Amalgam & 1 & $50.0 \%$ & 1 & $50.0 \%$ & \multirow{2}{*}{0.482} \\
\hline Composite & 27 & $73.0 \%$ & 10 & $27.0 \%$ & \\
\hline \multicolumn{6}{|l|}{ Two surface restoration use } \\
\hline Amalgam & 3 & $100.0 \%$ & 0 & $0.0 \%$ & \multirow{2}{*}{0.262} \\
\hline Composite & 23 & $69.7 \%$ & 10 & $30.3 \%$ & \\
\hline \multicolumn{6}{|l|}{ Three surface restoration use } \\
\hline Amalgam & 3 & $60.0 \%$ & 2 & $40.0 \%$ & \multirow{2}{*}{0.541} \\
\hline Composite & 22 & $73.3 \%$ & 8 & $26.7 \%$ & \\
\hline \multicolumn{6}{|c|}{$\begin{array}{l}\text { Which material do you use most often for complex restorations } \\
\text { ( } 4 \text { surface restorations)? }\end{array}$} \\
\hline Amalgam & 8 & $72.7 \%$ & 3 & $27.3 \%$ & \multirow{2}{*}{0.984} \\
\hline Composite & 21 & $72.4 \%$ & 8 & $27.6 \%$ & \\
\hline \multicolumn{6}{|c|}{$\begin{array}{l}\text { Which material did your clinical supervisor encourage you more often to } \\
\text { use? Give a reason for your answer. }\end{array}$} \\
\hline Composite & 29 & $72.5 \%$ & 11 & $27.5 \%$ & - \\
\hline
\end{tabular}


oral health care practitioners promote alternate materials such as composites, glass ionomers, and ceramics, especially in occlusal cavities and deciduous teeth. Quotas are set to guide work done by students, but patient choices inform the choice of materials used. As seen in our study, resin materials are, therefore, more widely used.

Best management practices should be employed for the safe disposal of amalgam and more oral health education on preventing caries, and supporting more research on the discovery of suitable alternative restorative materials should be offered..$^{24}$ In a previous study carried out in 2017, it was stated that dental amalgam no longer was the preferred material for the restoration of posterior teeth in South Africa. Resin composite was most widely used to repair or replace defective amalgam restorations. ${ }^{7}$ Composite was the preferred material, as is seen from the results of our study.
A recent study published in June 2019 determined the transition from amalgam to other restorative dental materials in the United States predoctoral paediatric dental clinics. This study was conducted among 44 dental schools. At the time of the study, the US dental schools did not appear ready to phase out dental amalgam training, and amalgam was still widely used in paediatric predoctoral training to restore both primary and permanent teeth. ${ }^{25}$ Teaching with dental amalgam continues at UKZN moreover in SA, and this is in line with many countries.

The results from this study have indicated that both the second- and third-year students have a sound knowledge of dental amalgam and other dental materials. The undergraduate restorative dentistry programme introduces resin composite as the first dental material that students are exposed to in the preclinical laboratory. This concurred with the study conducted in Israel, which found

\begin{tabular}{|c|c|c|c|c|c|}
\hline \multirow{3}{*}{ Variables } & \multicolumn{4}{|c|}{$\begin{array}{l}\text { Do you feel that resin composite should replace } \\
\text { amalgam in dental training? }\end{array}$} & \multirow{3}{*}{$\begin{array}{l}\text { Fisher } \\
\text { Exact } \\
\text { P-value }\end{array}$} \\
\hline & \multicolumn{2}{|c|}{ Yes } & \multicolumn{2}{|c|}{ No } & \\
\hline & $\mathbf{N}$ & $\%$ & $\mathbf{N}$ & $\%$ & \\
\hline \multicolumn{6}{|l|}{ Gender } \\
\hline Male & 2 & $66.7 \%$ & 1 & $33.3 \%$ & \multirow{2}{*}{0.476} \\
\hline Female & 8 & $44.4 \%$ & 10 & $55.6 \%$ & \\
\hline \multicolumn{6}{|c|}{$\begin{array}{l}\text { Do you think that you had adequate exposure to the various } \\
\text { types of restorative materials, used in the clinic? }\end{array}$} \\
\hline Yes & 6 & $46.2 \%$ & 7 & $53.8 \%$ & \multirow{2}{*}{0.155} \\
\hline No & 2 & $100.0 \%$ & 0 & $0.0 \%$ & \\
\hline \multicolumn{6}{|c|}{$\begin{array}{l}\text { Do you think that you had adequate training in the various types of cavity } \\
\text { design preparations? }\end{array}$} \\
\hline Yes & 7 & $53.8 \%$ & 6 & $46.2 \%$ & \multirow{2}{*}{0.466} \\
\hline No & 3 & $37.5 \%$ & 5 & $62.5 \%$ & \\
\hline \multicolumn{6}{|c|}{$\begin{array}{l}\text { What was the first dental material that you were introduced to in } \\
\text { the dental clinic? }\end{array}$} \\
\hline Amalgam & 3 & $42.9 \%$ & 4 & $57.1 \%$ & \multirow{2}{*}{0.757} \\
\hline Composite & 7 & $50.0 \%$ & 7 & $50.0 \%$ & \\
\hline \multicolumn{6}{|c|}{$\begin{array}{l}\text { How much of clinical training time was spent on the teaching } \\
\text { and training of amalgam? }\end{array}$} \\
\hline$<50 \%$ & 3 & $25.0 \%$ & 9 & $75.0 \%$ & \multirow{2}{*}{$0.017^{\star}$} \\
\hline$>50 \%$ & 7 & $77.8 \%$ & 2 & $22.2 \%$ & \\
\hline \multicolumn{6}{|c|}{ How much of clinical training time was spent on alternate dental materials? } \\
\hline$<50 \%$ & 1 & $33.3 \%$ & 2 & $66.7 \%$ & \multirow{2}{*}{0.563} \\
\hline$>50 \%$ & 9 & $50.0 \%$ & 9 & $50.0 \%$ & \\
\hline \multicolumn{6}{|l|}{ One surface restoration use } \\
\hline Amalgam & 0 & $0.0 \%$ & 1 & $100.0 \%$ & \multirow{2}{*}{0.329} \\
\hline Composite & 10 & $50.0 \%$ & 10 & $50.0 \%$ & \\
\hline \multicolumn{6}{|l|}{ Two surface restoration use } \\
\hline Composite & 10 & $47.6 \%$ & 11 & $52.4 \%$ & - \\
\hline \multicolumn{6}{|l|}{ Three surface restoration use } \\
\hline Amalgam & 2 & $50.0 \%$ & 2 & $50.0 \%$ & \multirow{2}{*}{0.919} \\
\hline Composite & 8 & $47.1 \%$ & 9 & $52.9 \%$ & \\
\hline \multicolumn{6}{|c|}{$\begin{array}{l}\text { Which material do you use most often for complex restorations (4 surface } \\
\text { restorations)? }\end{array}$} \\
\hline Amalgam & 3 & $42.9 \%$ & 4 & $57.1 \%$ & \multirow{2}{*}{0.757} \\
\hline Composite & 7 & $50.0 \%$ & 7 & $50.0 \%$ & \\
\hline \multicolumn{6}{|c|}{$\begin{array}{l}\text { Which material did your clinical supervisor encourage you more often to } \\
\text { use? Give a reason for your answer. }\end{array}$} \\
\hline Amalgam & 1 & $50.0 \%$ & 1 & $50.0 \%$ & \multirow{2}{*}{0.943} \\
\hline Composite & 9 & $47.4 \%$ & 10 & $52.6 \%$ & \\
\hline
\end{tabular}


that today some universities teach composite resin before introducing amalgam. ${ }^{26}$ This study's results indicated that dental amalgam is now less than $50 \%$ of the total practical time. Similar results were seen in the United Kingdom, where the researchers found that preclinical time for resin composite has increased since 1997. ${ }^{27}$

The researchers also concluded that composite might soon overtake or become the material of choice in posterior teeth. While competency was achieved and students felt competent enough to place restorations, certain factors hindered training. However, when the participants in our study were questioned about having sufficient exposure to place restorations, it emerged that students were happy with the lectures and tutorials given. However, they felt that there was not sufficient practical experience due to insufficient patients and larger class numbers. In a previous study conducted at the same site, it was found that there was an exponential rise in student numbers. ${ }^{17}$

Both the second- and third-year students indicated that their clinical supervisors encouraged them to use composite more often. This is in agreement with a previous study conducted, which also found a shift from dental amalgam to resin composites in dental training institutions. ${ }^{28}$ In another study conducted in Palestine, it was found that composite resin was used two to three times more than amalgam in the dental clinic.

The only time that it was found that amalgam was used more in the dental clinic was for complex restorations (more than three surfaces). Our study also showed that $35,3 \%$ of third-year students prefer to use amalgam for complex restorations ( 3 surfaces or more). ${ }^{25}$

One of the reasons for this factor has been that they have noticed that the 'younger' clinical supervisors encourage resin composite and the 'older' supervisors encourage dental amalgam. More research should be carried out in this regard. Another reason was that the clinical supervisors are preparing them for private practice, as more resin composite is used in private practice. This is in agreement with most second- and third-year students, who stated that they have seen composite being used more often in private practice.

Private dental practitioners showed an inclination to replace existing well-placed amalgam restorations with resin composites, as reported in earlier studies. ${ }^{29}$ The dental material of choice for simple, compound, and complex restorations was composite, which was indicated by most of the students in our study. The main reason for this was the ease of manipulation of the dental material. This was supported by the study conducted in Malaysia, which found that $49,2 \%$ of students preferred to use composite to restore posterior teeth, compared to $35 \%$ favoured amalgam. ${ }^{6}$

Nearly $36 \%$ of students in our study indicated a preference for amalgam in complex restorations. An Israeli study had similar results, where the researchers found that, in complex restorations, amalgam was still the material of choice. ${ }^{26}$
The majority of the third-year students were aware of the Minamata Convention and its implications, including the phase-down of dental amalgam. Most of the secondyear students had not heard of the Minamata Convention, and just $18 \%(n=7)$ were aware of the phase-down of dental amalgam.

This is concerning since the Minamata Convention advocated for the complete phase-down of amalgam by 2030. More emphasis regarding knowledge of this convention should be included in the second year curriculum training.

A study conducted in Jordan amongst second-year students found that only $13,8 \%$ of dentists knew about the Minamata Convention and only a few of them were aware of the phase-down of amalgam. ${ }^{30}$ However, almost half $(41,2 \% ; n=14)$ of third-year students were unsure of whether dental amalgam should completely replace composite in dental training.

Twenty-six percent of students agreed that amalgam should be replaced. The major contributing factor was aesthetics and the fact that dental composite was bonded to the tooth structure, resulting in minimal cavity preparations. This is also in agreement with the FDI policy on minimally intervention dentistry which requires the conservation of healthy tooth structure and to maintain healthy teeth for life.

Techniques such as lasers, chemo-mechanical caries removal, air abrasion and glass ionomer cement are some of the techniques used to conserve tooth structure. ${ }^{31}$ An amalgam restoration cavity design is extensive and does not follow minimal intervention techniques; however, a bonded amalgam does. Students also mentioned 'ease of use' (manipulation of the material) as another deciding factor in using dental composite.

Approximately twenty-one percent of students disagreed that amalgam should be replaced. The major reason is that dental amalgam was still considered the strongest dental material with the highest compressive strength. This is also evident from a study conducted in Saudi Arabia, which compared students' attitudes toward restorative materials and the future of amalgam and concluded that most students felt that amalgam could not be replaced entirely with composite. ${ }^{32}$

Amalgam is still a widely placed material in state-run oral health services. The complete phase-down of dental amalgam poses a threat to such services and threatens to widen oral health inequalities. ${ }^{33}$ This factor was iden tified by the participants in this study as well when they responded that dental amalgam was still being used in developing countries (South Africa and Brazil). Emphasis must be placed on preventing dental caries and promoting good oral health to minimise the need for restorations.

The dental curriculum is presently designed so that the core skills of preventive dentistry are introduced in the second year of study. The third year of dental therapy training focuses mainly on building clinical skills in relief of pain, sepsis (extractions), and restorative dentistry (fillings). 
The implications of these findings suggest that students need sustained exposure to preventive care in their undergraduate training to maximise greater awareness of caries prevention, more clinical exposure and a reduction in the use of amalgam. ${ }^{34}$ The researchers suggest that the curriculum be reviewed in this regard.

\section{Limitations of the study}

The study provided extensive insight into dental undergraduate students' knowledge regarding dental amalgam training's attitudes and practice, but some limitations were noted. The study focused exclusively on one dental school. Ideally, all dental schools (including students studying dentistry) should be included to gain all students' perspectives and the curriculum review regarding dental amalgam.

\section{CONCLUSION}

This study's findings indicated that both the second and third-year dental students were confident that they had adequate training to place restorations. A higher number of students prefer to place composite rather than amalgam restorations. The dental curriculum should be reviewed to ensure that the university keeps up with international trends, especially with the complete phase-down of dental amalgam.

Since dental amalgam is being phased out due to 'mercury toxicity, more research needs to be carried out on resin composite safety and its curing process before it can be hailed as 'the silver bullet' in restorative dentistry. An amalgam replacement material needs to be developed in the near future. More research is required to explore the clinical and pre-clinical learning environment further, taking into account the attitudes and perceptions of academics, patients and clinical supervisors, and recently graduated dental therapists.

\section{Declarations}

\section{Acknowledgements}

I would like to thank the participants who participated in this study.

\section{Funding}

The authors received no financial support for the research, authorship, and publication of this article.

\section{Authors' contributions}

SB was responsible for study design, data collection, data analysis, and drafting the manuscript. RM was responsible for the supervision of the entire work, study design and manuscript review.

All authors read and approved the final manuscript.

\section{Competing interests}

The authors declare that they have no competing interests.

\section{References}

1. Lynch CD, Frazier KB, McConnell RJ, Blum IR, Wilson NHF. State-of-the-art techniques in operative dentistry: contemporary teaching of posterior composites in UK and Irish dental schools. Br Dent J. 2010;209:129-136. https://doi. org/10.1038/sj.bdj.2010.674

2. World Health Organization. The World Health Report, 2008. Primary Health Care Geneva: WHO, 2008. Retrieved from https://www.who.int/whr/2008/en/ (Accessed on 03 November 2020)

3. Lombard R, du Preez IC, Oberholzer TG, Gugushe TS. Teaching approaches in South African dental schools: direct restorative procedures. SADJ. 2009; Feb: 64(1): 16,18-20. PMID: 19418898.

4. Fernandes NA, Vally Zi, Sykes LM. The longevity of restorations - A literature review. SADJ. 2015; 70(9): 410-3.

5. Hurst D. Amalgam or composite fillings - which material lasts longer? Evid Based Dent. Jun 2014; 15(2): 50 -1. doi: 10.1038/ sj.ebd.6401026. PMID: 24971858.

6. Mohammad N, Mohamed NN, Ruzmi NSM. Restorative Material Preference For Posterior Teeth Among Final Year Undergraduate Dental Students In Malaysian Public Universities. Jurnal Penyelidikan Sains Sosial (JOSSR). 2020; 3(6): 83-90. elSSN: 2637-0956.

7. Adam RZ, Naidoo S. The use and repair of dental amalgam restorations as practised in South Africa. SADJ. 2017; 72(8): 366-71. http://dx.doi.org/10.17159/2519-0105/2017/v72no8a4.

8. Auster P. Evolution and Revolution: Groundbreaking Changes in Composite Dentistry. Dentistry Today. Available from https ://www.dentistrytoday.com/articles/10522 (Accessed 19 March 2021).

9. United National Environment Programme. Minamata Convention On Mercury, October 2013. Retrieved from http://www. mercuryconvention.org/Portals/11/documents/Booklets/ Minamata\%20Convention\%20on\%20Mercury_booklet_ English.pdf (Accessed on 03 November 2020).

10. FDI policy statement on dental amalgam and the Minamata Convention on Mercury: Adopted by the FDI General Assembly: 13 September 2014, New Delhi, India FDI World Dental Federation. Int dental journal. Dec 2014; 64(6): 295-6. doi: 10.1111/idj.12151.

11. Ajiboye AS, Mossey PA; IADR Science Information Committee, Fox $\mathrm{CH}$. International Association for Dental Research Policy and Position Statements on the Safety of Dental Amalgam. J Dent Res. Jul 2020; 99(7): 763-8. doi: 10.1177/002 2034520915878.

12. Singh PK. The Dental Therapy Curriculum: Meeting Needs and Challenges for Oral Health Care in South Africa (PhD Thesis). University of KwaZulu-Natal; 2011. Retrieved from https://researchspace.ukzn.ac.za/xmlui/bitstream/handle/ 10413/6234/Singh_Pratima_Kissoon_2011.pdf?sequence= 1\&isAllowed=y (Accessed 29 October 2020).

13. Republic of South Africa. Government Gazette. Health Professions Act, 1974 (Act No. 56 Of 1974) Regulations Defining the Scope of the Profession of Dental Therapists, 1974. Retrieved from https://www.hpcsa.co.za/Uploads/DOH/Rules\% 20 and\%20Regulations/gg39979_nn512.pdf (Accessed on 03 November 2020).

14. Osbaldeston A. Reasons To Combine Qualitative And Quantitative Research, August 2018. Retrieved from https://www. questback.com/blog/5-reasons-to-combine-qualitative-andquantitative-research/ (Accessed on 03 November 2011).

15. Cochran WG: Sampling techniques: John Wiley \& Sons. 2007; ISBN: 978-0-471-16240-7.

16. Watson R. Quantitative research. Nurs Stand. 2015; 29(31): 44-8. doi: 10.7748/ns.29.31.44.e8681.

17. Masetla MM, Mthethwa SR. Dental Therapy Student cohorts: Trends in enrolment and progress at a South African University. SADJ. 2018; 73(6): 406-10. http://dx.doi.org/10.17 159/2519-0105/2018/v73no6a4. 
18. Alexander G, Hopcraft MS, Tyas MJ, Wong RHK. Dentists' restorative decision-making and implications for an 'amalgamless' profession. Part 1: a review. Aust Dent J. 2014 Dec; 59(4): 408-19. doi: 10.1111/adj.12209.

19. Walsh LJ, Brostek AM. Minimum intervention dentistry principles and objectives. Aust Dent J. Jun 2013; 58 Suppl 1: 3-16. doi: 10.1111/adj.12045. PMID: 23721333.

20. Alexander G, Hopcraft MS, Tyas MJ, Wong RHK. Dental educators' attitudes towards the teaching of dental amalgam. European Journal of Dental Education. 2020; 24(2): 282-91. https://doi.org/10.1111/eje.12496.

21. Ben-Gal G, Weiss El. Trends in material choice for posterior restorations in an Israeli dental school: composite resin versus amalgam. J Dent Educ. 2011. Dec; 75(12): 1590-5. PMID: 22184598.

22. Gbadebo SO, Anifowose OO, Ogunrinde TJ. Trend of posterior teeth restoration at Ibadan, Nigeria. J West Afr Coll Surg. Oct-Dec 2013; 3(4): 70-83. PMID: 26046026.

23. United Nations Environment Programme. Lessons from Countries Phasing Down Dental Amalgam Use. March 2016. Retrieved from https://zoinet.org/wp-content cuploads/2018/02/ Dental_Amalgam_pages.pdf (Accessed 27 October 2020).

24. The South African Dental Association. Dental Amalgam Position Statement, 2014. Retrieved from https://www.sada. co.za/Dental_Amalgam (Accessed 27 October 2020)

25. Kateeb ET, Warren JJ. The transition from amalgam to other restorative materials in the US predoctoral pediatric dentistry clinics. Clin Exp Dent Res. 2019; 5: 413-9. https://doi.org/10. 1002/cre2.196 .

26. Zabrovsky A, Neeman Levy T, Bar-On H, Beyth N, Ben-Gal G. Next generation of dentists moving to amalgam-free dentistry: Survey of posterior restorations teaching in North America. Eur J Dent Educ. Aug 2019; 23(3): 355-63. doi: 10.1111/ eje.12437.

27. Lynch CD, McConnell RJ, Wilson NH. Teaching of posterior composite resin restorations in undergraduate dental schools in Ireland and the United Kingdom. Eur J Dent Educ. Feb 2006: 10(1): 38-43. doi: 10.1111/j.1600-0579.2006.00394.x.

28. Ottenga ME, Mjör I. Amalgam and composite posterior restorations: curriculum versus practice in operative dentistry at a US dental school. Oper Dent. Sep-Oct 2007; 32(5): 524-8. doi: 10.2341/06-134.

29. Alkhudhairy F. Attitudes of dentists and interns in Riyadh to the use of dental amalgam. BMC Res Notes. 2016 Nov 17; 9(1): 488. doi: 10.1186/s13104-016-2294-x.

30. Al-Rabab'ah MA, Bustani MA, Khraisat AS, Sawair FA. Phase down of amalgam. Awareness of Minamata convention among Jordanian dentists. Saudi Med J. 2016 Dec; 37(12): 1381-6. doi: $10.15537 / \mathrm{smi} .2016 .12 .16163$.

31. Frencken JE, Peters MC, Manton DJ, Leal SC, Gordan WV, Eden E. Minimal intervention dentistry for managing dental caries - a review: report of a FDI task group. Int Dent J. 2012;62(5):223-43. doi: 10.1111/idj.12007.

32. Pani SC, Saffan AA, AlHobail S, Bin Salem F, AlFurain A, Al Tamimi M. Esthetic Concerns and Acceptability of Treatment Modalities in Primary Teeth: A Comparison between Children and Their Parents. Int J Dent. 2016; 3163904. doi: 10.1155/2016/3163904.

33. Aggarwal VR, Pavitt $S$, Wu J, et al. Assessing the perceived impact of post Minamata amalgam phase down on oral health inequalities: a mixed-methods investigation. BMC Health Serv Res. 2019; 19: 985. https://doi.org/10.1186/s12913-01 9-4835-1.

34. Moodley I, Singh S. Creating opportunities for interprofessional, community-based education for the undergraduate dental therapy degree in the School of Health Sciences, University of KwaZulu-Natal, South Africa: Academics' perspectives. Afr J Health Professions Educ. 2018; 10(1): 19-25. DOI:10.7196/AJHPE.2018.v10i1. 